\title{
A Multidisciplinary Dynamic Systems Curriculum
}

\author{
Timothy M. Cameron, Rosalyn S. Hobson, Gary S. Huvard \\ Virginia Commonwealth University
}

\begin{abstract}
Faculty in Chemical, Electrical and Mechanical Engineering collaborated in developing a new course, "Process and System Dynamics," and new dynamic systems laboratory exercises that can be used in a variety of courses and disciplines. The objective was to educate students in the fundamentals of dynamic systems and expose them to a broad diversity of applications in different disciplines. The labs are largely complete and are being used by students from different majors in several courses. After three offerings of "Process and System Dynamics," a new approach is being taken that provides common instruction on shared topics with disciplinespecific breakout sessions to cover unique disciplinary topics in depth. This paper discusses both the new course and the laboratory exercises, and shows how they are supporting the curricula of all three majors.
\end{abstract}

\section{Background}

Virginia Commonwealth University (VCU) dates its origin to 1815 with the establishment of the Medical College of Virginia. ${ }^{1}$ VCU is now composed of two campuses located in the capitol city of Richmond, Virginia: the Medical College of Virginia Campus located near the financial, governmental and retail district in downtown Richmond and the Academic Campus situated two miles west in the historic Fan District.

The VCU School of Engineering (SoE) was established in 1996 as an initiative of the University's strategic planning process in response to workforce and economic development needs of Richmond and central Virginia. ${ }^{2}$ The initial undergraduate programs in mechanical, electrical, and chemical engineering received ABET accreditation in 2001. The school added a new undergraduate major in biomedical engineering in the Fall of 1998, and VCU's long standing degree programs in Computer Science joined the SoE in the fall of 2001. In May of 2000 a graduate degree program in engineering was created and added to the historic graduate programs of biomedical engineering. With the admission of its sixth class in the Fall of 2001, the SoE now enrolls over 1000 students. The first two of the new school's planned facilities opened in the Fall of 1998 - the main classroom building and the Virginia Microelectronics Research Center. Together, they total 147,000 sq. $\mathrm{ft}$. at a cost of $\$ 42$ million. Average SAT scores of incoming freshman are about 1250 , which is in the national top 5 to 7 percentile.

From the beginning, the development of the School was a collaboration between the university and the industrial community, which is reflected in its curriculum, in the industrial experience students have available, in the inclusion of business courses in the engineering curriculum, and the recruitment of faculty with industrial experience. Over 50 companies have hired SoE graduates and almost 100 companies have offered internship placements for students. In addition to permanent placements and student internships in industry, the SoE has been engaged in detailed technical exchanges with Infineon, Ethyl, Dominion Virginia Power, MacroSonix, 
Cyberclean, and Motorola. Engineers from industry are also working with the school's faculty to teach courses with direct relevance to industry.

With an emphasis on diversity and collaboration, there was an initial optimism that the opportunity to build new programs from scratch in chemical, electrical and mechanical engineering would allow great efficiency by integrating courses with similar content in different disciplines. Initial efforts at jointly teaching thermodynamics, fluid mechanics and heat transfer between chemical and mechanical engineering failed. Faculty in the two disciplines felt that the subject matter needed to be directed toward the primary applications in their own disciplines, and students complained that they could not understand the material presented in the other discipline, or that the material was irrelevant. The one successful collaboration, now in its fourth year, is the effort to unify as much as possible the dynamic systems and controls curricula of chemical, electrical and mechanical engineering.

\section{Objectives}

The goal of this effort has been to unify the dynamic systems and controls courses of chemical, electrical and mechanical engineering while still allowing some discipline-specific specialization. The vision is to create a modern integrated curriculum and laboratory learning environment that promotes critical reasoning and problem solving skills, and apply these skills to the modeling, analysis, design, measurement, control and management of complex dynamic systems.

The specific focus of the program is on the development of a common required course, Process \& Systems Dynamics, for chemical, electrical and mechanical engineering students, and three discipline-specific laboratory courses. The discipline-specific required courses - Unit Operations Laboratory for chemical engineering, Automatic Controls for electrical engineering, and Engineering Synthesis Laboratory for mechanical engineering - allow specialization at the advanced level, but preserve an interdisciplinary perspective by sharing experiments and projects. Students emerge from the sequence with a firm understanding of the physical principles underlying engineering processes, and practical experience in the design, fabrication and testing of tangible products that synthesize multidisciplinary features.

Within the larger scope of the engineering curricula, separate disciplines steer in to the dynamic systems sequence with some specialization - electrical engineers take Signals \& Systems, and chemical and mechanical engineers take Sensors \& Measurements. Coming out of the sequence there are additional electives, such as Robotics, Introduction to Manufacturing Systems, and Control System Design, which are highly interdisciplinary while still providing the specialization necessary to the topic.

This paper summarizes the current status of the integrated curriculum and presents the course syllabus for "Process and System Dynamics," along with the labs that have been developed so far for the subsequent discipline-specific laboratory courses. 


\section{Process \& Systems Dynamics}

The catalog description" of "Process \& Systems Dynamics" reads:

ENGR 315 Process and Systems Dynamics Semester course; 3 lecture hours. 3 credits. Prerequisite: MATH 301 [Differential Equations]. Undergraduate course covering the analysis of chemical, fluid, mechanical and electrical dynamic systems. Pedagogically, a single approach is taught that applies to any of the systems in any of these disciplines using conservation equations and constitutive relationships to build the systems of differential equations needed for the analysis. The mathematical structures of the types of differential equations typically generated in dynamic physical systems are reviewed and both analytical and numerical solution techniques are taught. Finally, the tools used to develop control components for systems in these areas are covered along with the mathematical tools (e.g., Laplace transforms) needed for their analysis.

The use of conservation equations as a unifying principle for multidisciplinary systems is adapted from work done with the NSF Foundation Coalition by Charles Glover of Texas A\&M and Don Richards of Rose-Hulman. ${ }^{4-7}$ The governing equations of electrical circuits, statics, dynamics, thermodynamics, fluid mechanics, and heat transfer (e.g., Kirchoff's laws, Newton's laws and the Navier-Stokes equation) are shown to follow from conservation of mass, momentum and energy in combination with constitutive and transducer laws and causality.

The syllabus of Process \& Systems Dynamics was originally intended to be the same for chemical, electrical and mechanical engineering students. Discipline-specific variations would be covered in later courses. However, industrial advisors to Chemical Engineering requested more content oriented to pumps and valves for process industries, so for Spring 2003 the first eleven weeks of the semester are common to all three disciplines, but for the last five weeks the chemical engineering students separate, while the electrical and mechanical students remain together. The course syllabus is shown in Table 1. In weeks 12-16 the chemical engineering students study process equipment while the mechanical and electrical students study modeling. The class meets twice a week for an hour and a half. Seventy-four students are enrolled for the Spring 2003 semester.

\section{Discipline-Specific Laboratory Courses}

Most of the discipline-specific content of the dynamic systems curriculum is covered in senior level courses with a large laboratory component. Chemical engineers focus on process control (heat exchange, mixing, distillation, etc.) electrical engineers focus on motor control, and mechanical engineers focus on servo-control (linear and rotational position and velocity) and climate control. There is still a fair amount of overlap in this material, so laboratories developed in each discipline are available to faculty in other disciplines. The concept is to have a "Chinese menu" of laboratories available to all faculty for their courses. Due to the relatively small size of the VCU School of Engineering the logistics of making laboratory exercises available to the whole school, crossing disciplinary lines, it not a difficult problem to surmount since the labs are not in constant use. 
Table 1. ENGR-315, Process \& Systems Dynamics, Course Syllabus (Electrical/Mechanical)

\begin{tabular}{|c|c|c|}
\hline Week & \multicolumn{2}{|c|}{ Topic } \\
\hline 1 & \multicolumn{2}{|c|}{ Introduction to Dynamic Systems Modeling, Analysis, and Control } \\
\hline & \multicolumn{2}{|l|}{ Review of differential equations } \\
\hline 2 & \multicolumn{2}{|l|}{ Laplace transforms and the meaning of "s" } \\
\hline & \multicolumn{2}{|l|}{ Free response: first, second, and higher order systems } \\
\hline 3 & \multicolumn{2}{|l|}{ Forced transient response and frequency response } \\
\hline & \multicolumn{2}{|c|}{ Dynamic systems structure, impedance, transfer functions, and block diagrams } \\
\hline 4 & \multicolumn{2}{|c|}{ Nonlinear systems, linearization, and stability (application of Taylor series) } \\
\hline & \multicolumn{2}{|c|}{ State-space formulation and numerical integration (Mathcad, Matlab, and EZSolve) } \\
\hline 5 & \multicolumn{2}{|c|}{ Feedback control systems: representation, sensors, and actuators } \\
\hline & \multicolumn{2}{|c|}{\begin{tabular}{|l} 
Test 1: Mathematics of Linear Systems \\
\end{tabular}} \\
\hline 6 & \multicolumn{2}{|l|}{ Control logic and control of a first-order plant } \\
\hline & \multicolumn{2}{|l|}{ Control of a second order plant } \\
\hline 7 & \multicolumn{2}{|l|}{ Electronic, pneumatic, and hydraulic controllers } \\
\hline & \multicolumn{2}{|l|}{$\mathrm{P}$ and $\mathrm{PI}$ control, error rates } \\
\hline 8 & \multicolumn{2}{|l|}{ PID control, error rates } \\
\hline & \multicolumn{2}{|l|}{ Performance indices and controller tuning } \\
\hline 9 & \multicolumn{2}{|c|}{ Spring Break } \\
\hline 10 & \multicolumn{2}{|l|}{ Command compensation and disturbance compensation } \\
\hline & \multicolumn{2}{|l|}{ Feedback compensation and cascade control } \\
\hline 11 & \multicolumn{2}{|l|}{ Reset wind-up and actuator saturation } \\
\hline & \multicolumn{2}{|c|}{\begin{tabular}{|c|c|} 
Test 2: Control of Linear Systems \\
\end{tabular}} \\
\hline \multirow[t]{3}{*}{12} & EE \& ME & ChE \\
\hline & Mechanical systems modeling; generalized impedance & Sensors and transmitters \\
\hline & Transducers: transformers and gyrators & Types of control valves and Cv \\
\hline \multirow[t]{2}{*}{13} & Electrical circuit modeling and op-amps & Control valve sizing \\
\hline & Analogies among physical systems; conservation laws & Feedback controllers \\
\hline \multirow[t]{2}{*}{14} & Multidisciplinary systems; Electro-mechanical systems & Process and control system simulation \\
\hline & Hydraulic and pneumatic systems & Computer simulation of PID controllers \\
\hline \multirow[t]{2}{*}{15} & Electro-mechanical-hydraulic systems & Tuning PID controllers, reset windup \\
\hline & Thermal systems & Cascade control, feedforward control, adaptive control \\
\hline 16 & Test 3: Dynamic Systems Modeling & Test 3: Process Modeling and Control \\
\hline
\end{tabular}

Unit Operations Laboratory The Chemical Engineering lab-intensive course in the dynamic systems curriculum is EGRC-340L, Unit Operations Laboratory, taught by Gary Huvard. Dr. Huvard has nearly completed the manual for this course, and a draft copy is available upon request. ${ }^{8}$ The unit operations experiments are listed in Table 2. A photograph of the unit operations "skid" that contains most of the laboratory equipment is shown in Figure 1.

Automatic Controls Laboratory The lab-intensive electrical engineering course in the dynamic systems curriculum is EGRE-454, Automatic Controls, taught by Dr. Rosalyn Hobson. The Automatic Controls laboratories are listed in Table 3, and copies of the lab handouts are available upon request. ${ }^{9}$ The controls laboratories focus on analog control using op-amp circuits, and are primarily oriented around DC motors. Figure 2 shows one of the experimental units used for the analog control labs. Dr. Hobson is also developing digital control labs. 
Table 2. EGRC-340L, Chemical Engineering Unit Operations Laboratory Experiments

\begin{tabular}{|c|l|}
\hline Experiment & \multicolumn{1}{c|}{ Description } \\
\hline 0 & Laboratory Acclimation, PFDs, P\&IDs, and Theory Review \\
\hline 1 & Effluent Transfer System Hydraulics \\
\hline 2 & Alfa Laval Plate \& Frame Heat Exchanger \\
\hline 3 & Agitated Tank Heat Transfer \\
\hline 4 & Thickener/Clarifier Sizing from Sedimentation Tests \\
\hline 5 & Rotary Vacuum Filter Sizing \\
\hline 6 & Gravity Flow Head Tank Hydraulics \\
\hline 7 & Mixing I \\
\hline 8 & Batch Vacuum Drying \\
\hline 9 & Crystallization (in preparation) \\
\hline
\end{tabular}

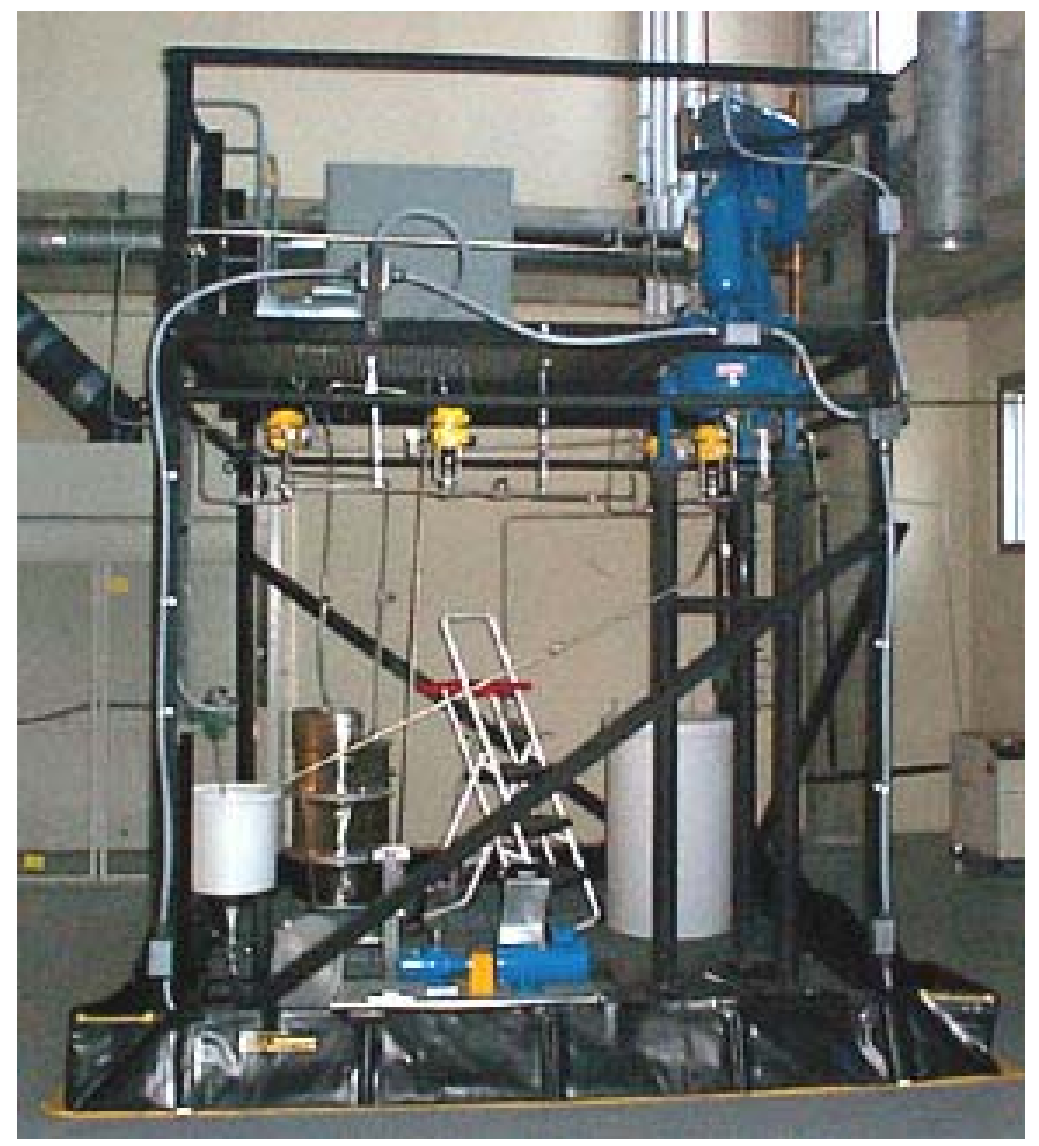

Figure 1. Chemical Engineering Unit Operations "Skid" 
Table 3. EGRE-454, Automatic Controls, Laboratory Exercises

\begin{tabular}{|c|l|}
\hline Experiment & \multicolumn{1}{c|}{ Description } \\
\hline 1 & Pulse Width Modulation of a High Power DC Motor \\
\hline 2 & DC Motor Analog Op-Amp-Based Speed Control \\
\hline 3 & Unipolar Stepper Motor Control using a 5804 Chip \\
\hline 4 & Error Channel, Feedback Polarity, Gain, and Velocity Feedback \\
\hline 5 & System Following Error, Unstable Systems, and System Speed Control \\
\hline 6 & 3-Term (PID) Control Action: Part I, Introduction \\
\hline 7 & 3-Term (PID) Control Action: Part II, Applications \\
\hline
\end{tabular}

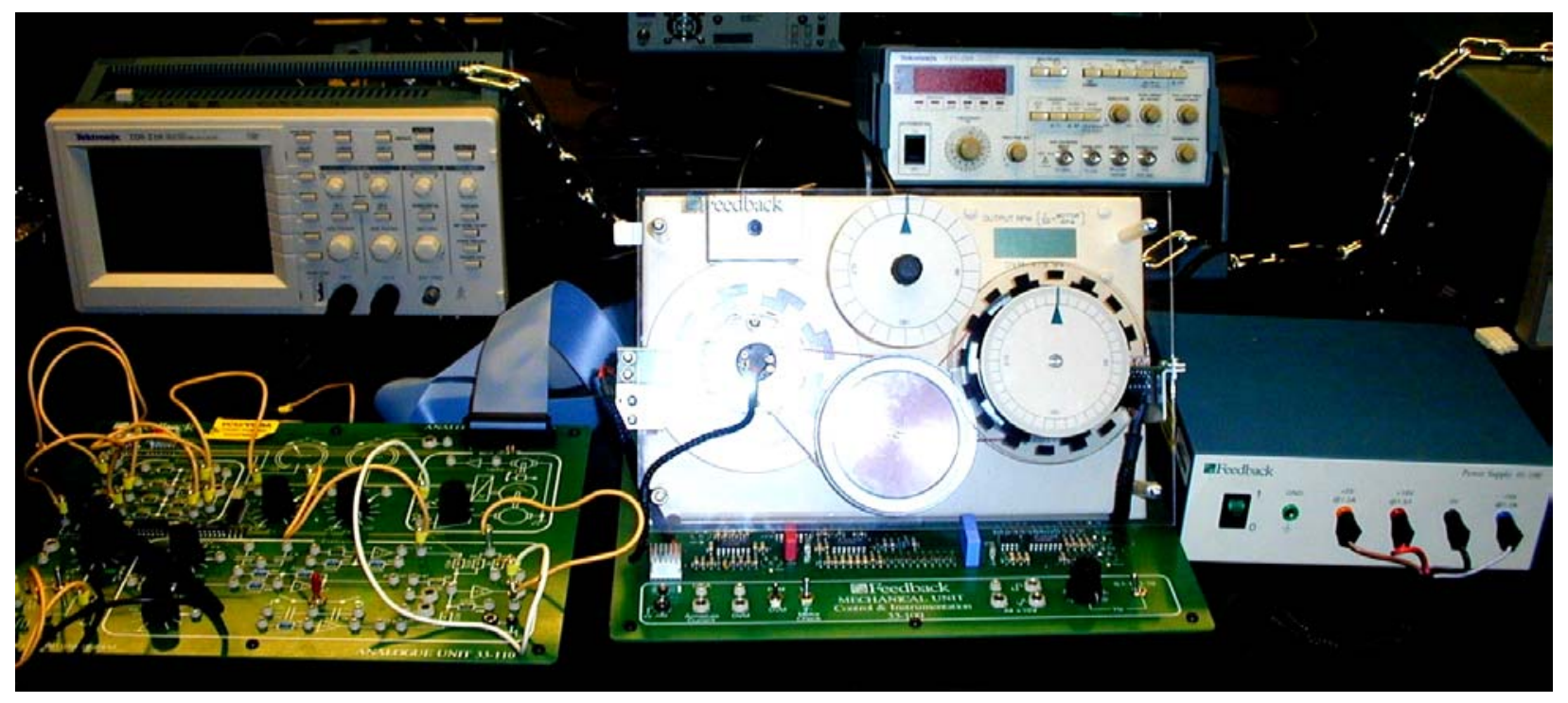

Figure 2. Analog Feedback Motor Control System

Engineering Synthesis Laboratory The mechanical engineering course in the dynamic systems curriculum is EGRM-410, Engineering Synthesis Laboratory. The laboratory exercises in this course (Table 4) fall into three categories, (i) Refrigeration and Air Conditioning, (ii) Sensors and Closed-Loop Feedback Logic-based Control, and (iii) Integrated Circuits for Servomotor Control. Laboratory handouts are available upon request. ${ }^{10}$ Labs 7 and 8 in the mechanical engineering course are the same as labs 1 and 3 in the electrical engineering controls course, and use the same facilities. The EPA regulates the handling of refrigerants, so faculty and staff involved in running the Refrigeration and Air Conditioning laboratories have EPA certification and training in the recovery and recycling of refrigerants. ${ }^{11}$ Figure 3 shows one of the air conditioning systems.

The lecture portion of this course focuses on the emerging discipline of mechatronics. ${ }^{12-13}$ and many students use this foundation for their senior design projects. For one project, sponsored by John Deere, students designed and built a dual powered (solar and battery) refrigerator that rides in the back of a golf cart. A control system automatically switches to battery power when solar power is insufficient to operate the refrigerator. 
Table 4. EGRM-410, Engineering Synthesis Laboratory, Lab Exercises

\begin{tabular}{|c|l|}
\hline Experiment & \multicolumn{1}{c|}{ Description } \\
\hline 1 & Refrigeration \& A/C \#1: System Setup, Equipment \& Refrigerants \\
\hline 2 & Refrigeration \& A/C \#2: System Operation and Control (Heat Pump) \\
\hline 3 & Refrigeration \& A/C \#3: Semi-Hermetic \& Ductless Split Systems \\
\hline 4 & Sensors and Measurement Instruments (overview and review) \\
\hline 5 & Open- vs. Closed-Loop Control using Lego Mindstorms \\
\hline 6 & Logic-based Control using Lego Mindstorms \\
\hline 7 & Pulse Width Modulation Control of DC Motors (3525 IC \& MOSFET) \\
\hline 8 & Unipolar Stepper Motor Control (5804 IC) \\
\hline 9 & AC and Brushless DC Motors (2936-120 IC) \\
\hline
\end{tabular}

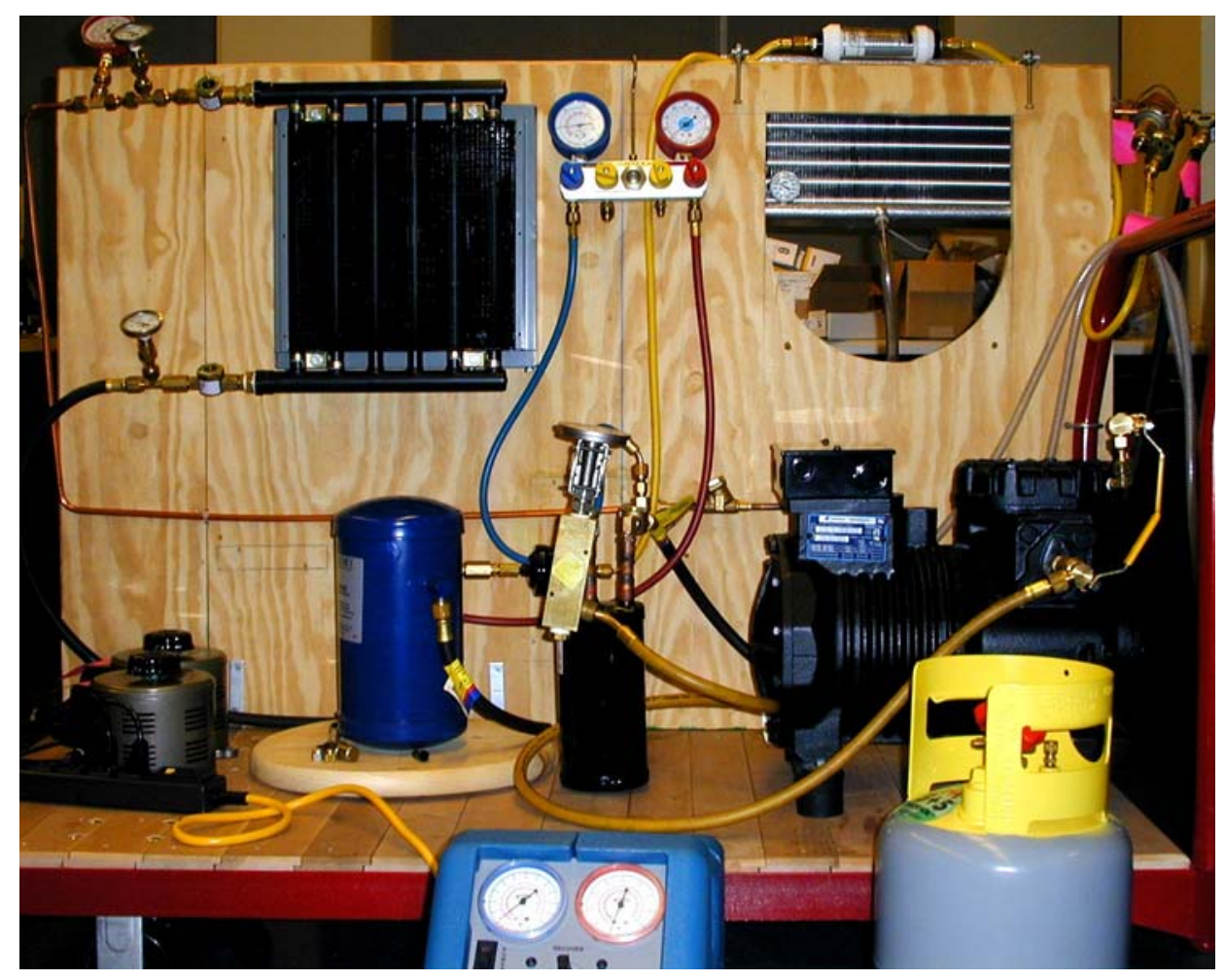

Figure 3. Semi-Hermetically Sealed Air Conditioning System

\section{Discussion}

The Dynamic Systems and Controls curriculum in the VCU School of Engineering is a successful multidisciplinary collaboration of faculty in chemical, electrical and mechanical engineering. Each curriculum establishes its own pre-requisite path to ENGR-315, Process \& Systems Dynamics, which serves as the core course uniting the multidisciplinary curriculum. Students in chemical, electrical and mechanical engineering get the same foundation in the mathematics of linear systems $\left(1^{\text {st }}, 2^{\text {nd }}\right.$ and higher order systems, linearization of nonlinear systems, and simulation tools), control of linear systems including compensator design and 
tuning, and mathematical modeling of dynamic systems. Each program has developed its own laboratory-intensive, discipline-specific course, but the laboratory exercises developed for these courses provide a "Chinese menu" of laboratories that all faculty can use in their courses either as labs or as demonstrations. Electrical and mechanical engineering share several of the motor control labs. The refrigeration and air-conditioning labs in mechanical engineering are used for demonstrations in the thermodynamics, fluid mechanics and heat transfer courses. Additional lab sharing is also anticipated between chemical and mechanical engineering. These courses serve approximately seventy-five students a semester, and have been in development for three to four years. Many students use their foundation in dynamic systems and controls for their senior design projects. The authors believe that this effort can serve as a model for small to mid-size engineering schools that can share laboratories and equipment across departments.

\section{Acknowledgments}

This worked was supported in large part by NSF CCLI grant 0088378 . Bowlin Thompson, a mechanical engineering student, and Chris Green, the School of Engineering laboratory technician, made major contributions to the development of the motor control and refrigeration laboratories.

\section{Bibliography}

1. VCU Office of Institutional Research and Evaluation, "Brief History of VCU," http://www.vcu.edu/ireweb/factcardtabs/AboutVCU.htm

2. VCU School of Engineering, http://www.egr.vcu.edu/general/aboutus_main.html

3. Virginia Commonwealth University Undergraduate and Professional Programs Bulletin and Website, Virginia Commonwealth University, Richmond, VA, 2002, http://www.vcu.edu/bulletins/200203/ub/

4. C. J. Glover and D. E. Richards, "Conservation Law-Based Integrated Sophomore Curricula," Foundation Coalition Summer Curriculum Workshop, Sessions 4 \& 5, LeBaron Hotel, Colorado Springs, CO, August 6-8, 1998.

5. Conservation Principles and the Structure of Engineering, Fifth Edition, Glover, Lunsford and Fleming, McGraw Hill, 1996.

6. Conservation Principles: http://aeromaster.tamu.edu/haisler/engr211/

7. Foundation Coalition: http://www.foundationcoalition.org/

8. Send requests for the Chemical Engineering "Unit Operations Manual” to Dr. Gary Huvard, gshuvard@vcu.edu.

9. Send requests for the "Automatic Controls Laboratory" Handouts to rshobson@vcu.edu

10. Requests for “Engineering Synthesis Laboratory” Handouts: tmcamero@vcu.edu

11. Clean Air Act, Section 608

12. Textbook: Michael B. Histand and David G. Alciatore, Introduction to Mechatronics and Measurement Systems, $2^{\text {nd }}$ ed., McGraw-Hill, 2003.

13. For helpful materials on mechatronics, developed by the NSF Synthesis Coalition, visit http://www.synthesis.org/Mechatronics.html. 


\section{Biographical Information}

TIMOTHY M. CAMERON is Associate Professor and Assistant Chair of Mechanical Engineering at Virginia Commonwealth University. He joined the ME faculty in January 1999 after teaching at Kettering University and holding technical and managerial positions at Algor Inc. and Ansoft Corp. His teaching and research interests include dynamic systems, controls, acoustics, vibration, optimization, modeling and simulation.

ROSALYN S. HOBSON is an Assistant Professor of Electrical Engineering at Virginia Commonwealth University. She has worked extensively in course and curriculum development. She was chosen as a Frontiers in Education (FIE) New Faculty Fellow in 2000 and was awarded the 2001 Dr. Janice A Lumpkin Educator of the Year.

GARY S. HUVARD is an Associate Professor of Chemical Engineering at Virginia Commonwealth University in Richmond, Virginia. He joined the Chemical Engineering faculty at VCU in January 1999 after 10 years in technical positions with BFGoodrich and duPont and 10 years in private practice. His research interests include diffusion in polymers and chemical reaction engineering. 